\title{
Vegetable oil based liquid nanocomposite dielectric
}

AUTHORS:

Leon Chetty ${ }^{1}$

Isaac W. Serukenya'

Nelson M. ljumba ${ }^{1}$

\section{AFFILIATION:}

${ }^{1}$ HVDC Centre, University of KwaZulu-Natal, Durban, South Africa

\section{CORRESPONDENCE TO: Leon Chetty}

\section{EMAIL:}

chettyl2@ukzn.ac.za

\section{POSTAL ADDRESS:}

HVDC Centre, Printing Services Building, Westville Campus University of KwaZulu-Natal, Durban 4001, South Africa

\section{DATES:}

Received: 15 May 2012

Revised: 05 Aug. 2012

Accepted: 27 Aug. 2012

\section{KEYWORDS:}

power transformer; vegetable insulating oil; nanodielectrics; liquid nanocomposite dielectric silica aerogel powder

\section{HOW TO CITE:}

Chetty L, Serukenya WI, ljumba NM. Vegetable oil based liquid nanocomposite dielectric. S Afr J Sci. 2013;109(1/2), Art. \#1274, 6 pages. http://dx.doi. org/10.1590/sajs.2013/1274

(C) 2013. The Authors. Published under a Creative Commons Attribution Licence.
Physically smaller dielectric materials would improve the optimisation of space for power systems. Development of nanotechnology provides an effective way to improve the performances of insulating oils used in power system applications. In this research study, we focused on the development of nanomodified vegetable oils to be used in power transformers. Higher conduction currents were observed in virgin linseed oil than in virgin castor oil. However, for both virgin linseed and virgin castor oil, the DC conduction current increased approximately linearly with the applied DC voltage. In nanomodified linseed oil, the characteristic curve showed two distinct regions: a linear region (at lower applied voltage) and a saturation region (at slightly higher voltage). Conversely, in nanomodified castor oil, the characteristic curve showed three distinct regions: a linear region (at lower applied voltage), a saturation region (at intermediate applied voltage) and an exponential growth region (at higher applied voltage). The nanomodified linseed oil exhibited a better dielectric performance than the nanomodified castor oil. Overall, the addition of nanodielectrics to vegetable oils decreased the dielectric performance of the vegetable oils. The results of this study contribute to the understanding of the pre-breakdown phenomenon in liquid nanocomposite dielectrics.

\section{Introduction}

One of the key stimulants to the growth of an economy is the availability of affordable and reliable electricity. ${ }^{1}$ The availability of electricity is being handled by various governmental endeavours to fund grid extension projects particularly to rural areas. ${ }^{1}$ Construction costs of grid extension are influenced by the availability of space. Generation plants are generally located at a significant distance from the customer load networks; therefore longdistance transmission systems are implemented at high voltage so as to minimise power losses. The challenges of high-voltage transmission systems are a wide right of way and long safety clearances. The prevailing high cost of land and concerns of environmentalists about the effect of such high-voltage installations on the environment have necessitated a preference for more compact high-voltage substations. ${ }^{2,3}$ The achievement of compact high-voltage substations is constrained by the ability of the insulation materials used to withstand high electrical stresses. Research over the years in respect of high-voltage transmission systems has been focused on developing innovative ways of modifying the properties of insulation materials. ${ }^{4}$ The general approach has been to attempt to use thinner or less material to withstand high electrical stresses. ${ }^{4}$ Physically smaller dielectric materials would improve on the optimisation of space for the generation, transmission and distribution of electricity.

The primary components of high-voltage equipment are (1) the conducting parts and (2) the insulation component or dielectric material. The dielectrics used in high-voltage equipment can be solid, liquid or gaseous. In this study, we focused on oil insulation for high-voltage equipment such as power transformers. In a typical power system, transformer failure would result in thermal overload and possible voltage instability and transient instability. ${ }^{5}$ The most common cause of transformer outage is insulation failure. ${ }^{6}$ The insulation failure may arise from insulation deterioration and subsequent dielectric breakdown. ${ }^{6,7}$ Improving the performance of the liquid dielectric would increase the reliability of the transformer which subsequently would positively contribute to a reduction of power system losses.

Historically, petroleum-based mineral oils were purified to 'transformer oil grade' and used as dielectrics in liquidfilled transformers. As a measure of the popularity of mineral oil, a significant quantity of petroleum-based oil is used globally in transformers. The main reason for this popularity has been related to its availability. Despite its popularity, there is growing concern that the supply of petroleum-based transformer oil will diminish. There have been significant concerns regarding the impact of petroleum-based transformer oil on the environment, particularly in cases of spills that could contaminate soil and waterways, because petroleum-based transformer oil is poorly biodegradable. ${ }^{8,9}$ For these reasons, current research has been focused on obtaining biodegradable sources of insulating fluids, such as vegetable oils. ${ }^{8-15}$ Recently, vegetable oils have been investigated for use in power transformers. ${ }^{8-15}$ The main motivation for investigating the use of vegetable oils in transformers has been the environmental concerns relating to transformer oil spillage around coastal regions..$^{10,11}$

The pre-breakdown phenomenon in petroleum-based transformer oil has also been investigated extensively. ${ }^{16-20}$ During the pre-breakdown phenomenon, microscopic gaseous bubbles are formed at the electrodes. ${ }^{18,19}$ At low electric fields these bubbles expand slightly and detach from the electrodes and are swept into the oil. ${ }^{18,19}$ At high electric fields, streamers are formed. Streamers are collections of microscopic bubbles and are filamentary or bushlike in nature..$^{19}$ The majority of streamers does not propagate across the electrode gap. ${ }^{19}$ Streamer propagation is dependent on the applied voltage, which also determines the length at which the streamer will stop propagating. ${ }^{18}$ Current pulses occur only during the growth phase of the streamer development. ${ }^{16}$ If breakdown does not occur, the current pulse burst ceases as the streamer stops propagating. ${ }^{16}$ The pre-breakdown current characteristics can be summarised by conduction current measurements. ${ }^{20-22}$

In this research study, the silica aerogel powder, which is a nanodielectric, was manufactured in our university laboratory. The silica aerogel powder was then added to two different vegetable oils - linseed oil and castor oil - to form liquid nanocomposite dielectrics. The influence of the nanodielectric on the vegetable oils was analysed by measuring the DC conduction. 


\section{Silica aerogel}

Silica aerogel is a unique porous material consisting of $90 \%$ air and less than $10 \%$ solid silica that exists in a highly cross-linked network structure. ${ }^{23}$ It is made up of spherical particles of primary particle diameter of 2-5 nm fused together into clusters which form a porous three-dimensional, open cross-linked silica structure with a high fraction of voids with fine pore sizes. ${ }^{24}$ As a result of its physical structure, silica aerogel has unique weight and thermoelectrical properties (Table 1).

Table 1: $\quad$ Physical properties of silica aerogel

\begin{tabular}{|c|c|c|}
\hline Property & Value & Comment \\
\hline Apparent density & $0.003-0.35 \mathrm{~g} / \mathrm{cm}^{3}$ & $\begin{array}{l}\text { The most common density } \\
\text { is } \sim 0.1 \mathrm{~g} / \mathrm{cm}^{3} \text {, which } \\
\text { makes it the lightest known } \\
\text { dielectric material }\end{array}$ \\
\hline $\begin{array}{l}\text { Internal surface } \\
\text { area }\end{array}$ & $600-1000 \mathrm{~m}^{2} / \mathrm{g}$ & $\begin{array}{l}\text { Determined by nitrogen } \\
\text { adsorption/desorption (very } \\
\text { high surface area) }\end{array}$ \\
\hline \% Solids & $0.13-15 \%$ & $\begin{array}{l}\text { Typically } 5 \% \text { (95\% free } \\
\text { space) }\end{array}$ \\
\hline $\begin{array}{l}\text { Mean pore } \\
\text { diameter }\end{array}$ & $\sim 20 \mathrm{~nm}$ & $\begin{array}{l}\text { As determined by nitrogen } \\
\text { adsorption/desorption } \\
\text { (varies with density) }\end{array}$ \\
\hline Pore channels & $\begin{array}{l}10-100 \mathrm{~nm} \text { in } \\
\text { diameter }\end{array}$ & $\begin{array}{l}\text { Open pores (i.e. the pores } \\
\text { are interconnected by } \\
\text { channels) }\end{array}$ \\
\hline $\begin{array}{l}\text { Primary particle } \\
\text { diameter }\end{array}$ & $2-5 \mathrm{~nm}$ & $\begin{array}{l}\text { Determined by electron } \\
\text { microscopy }\end{array}$ \\
\hline $\begin{array}{l}\text { Dielectric } \\
\text { constant }\end{array}$ & $\sim 1.1-2.2$ & $\begin{array}{l}\text { Very low for a solid material } \\
\text { (for density }=0.1 \mathrm{~g} / \mathrm{cm}^{3} \text { ) }\end{array}$ \\
\hline $\begin{array}{l}\text { Thermal } \\
\text { conductivity }\end{array}$ & $<0.1 \mathrm{~W} / \mathrm{mK}$ & $\begin{array}{l}\text { One of the lowest thermal } \\
\text { conductivities for a } \\
\text { solid material }\end{array}$ \\
\hline
\end{tabular}

Sources: Ivanov et al. ${ }^{24}$, Wei et al. ${ }^{25}$, Faez et al. ${ }^{26}$

\section{Preparation of silica aerogel}

The two chemical processes that lead to formation of silica aerogel are: (1) the 'sol-gel' process which involves the formation of a 'wet' gel from a silica base (i.e. gelation) by cross-linking of siloxane bridges pursuant to hydrolysis and condensation reactions and (2) the drying process which involves the formation of the silica aerogel from the 'wet' gel by extracting the pore liquid from within its pores under ambient pressure and ambient temperature. ${ }^{27}$

\section{The sol-gel process}

To initiate the sol-gel process, the following were mixed to form a sol: $17.38 \mathrm{~mL}$ tetra ethyl orthosillicate (TEOS; reagent grade 98\%, Sigma Aldrich, St. Louis, MO, USA), $52.14 \mathrm{~mL}$ absolute ethanol (99.9\% pure), $0.52 \mathrm{~mL}$ of 1 molar hydrochloric acid (HCL; Merck, Frankfurt, Germany) and $69.52 \mathrm{~mL}$ of deionised water. The sol was placed in an oven at $40^{\circ} \mathrm{C}$ to allow for progression of the hydrolysis and condensation reactions. After $1.5 \mathrm{~h}, 3.6 \mathrm{~mL}$ of ammonium hydroxide was added so as to catalyse the condensation reaction. Volumes of $4.5 \mathrm{~mL}$ of TEOS and $3.4 \mathrm{~mL}$ of ethanol were added immediately after the ammonium hydroxide solution to enhance the formation of the siloxane bridges, thereby maximising the cross-linking. The temperature of the oven was regulated at $40{ }^{\circ} \mathrm{C}$. This temperature led to the formation of a firm gel within 18-20 h. The gel must be allowed sufficient time for all hydrolysis and condensation reactions to attain completion in order for the silica network within the gel to strengthen, such that it is able to hold up under its own weight without a mould. This process is referred to as 'aging' (Figure 1). Aging was carried out by soaking the gel in ethanol for $24 \mathrm{~h}$ at $40^{\circ} \mathrm{C}$.

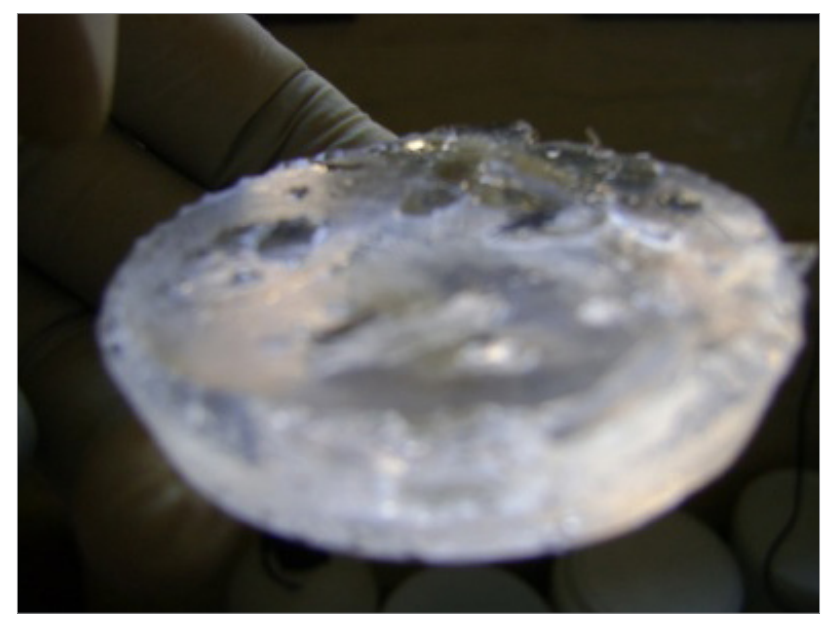

Figure 1: Silica gel after aging.

After aging, the gel had a hydrophilic surface as a result of the presence of a hydroxyl group. A hydrophilic surface is not a desirable property for an insulating material. To obtain a hydrophobic property, a surface modification process was carried out. In preparation for surface modification, a solvent exchange process was carried out by soaking the gel in $63 \mathrm{~mL}$ of $\mathrm{n}$-hexane for $24 \mathrm{~h}$. This process was repeated three times to allow sufficient time for extraction, by diffusion, of the ethanol as well as any other unreacted chemicals entrapped within the pores of the gel. The gel was then immersed in a solution of $63 \mathrm{~mL}$ of $\mathrm{n}$-hexane, $2 \mathrm{~mL}$ of trimethylchlorosilane and $4.8 \mathrm{~mL}$ of absolute ethanol. This solvent exchange enabled substitution of the hydroxyl group on the gel surface by a hydrophobic functional group, i.e. surface modification. The unreacted chemicals and liquid products of the surface modification reactions were extracted from within the pores of the gel by carrying out a solvent exchange. In this study, this was achieved by adding $63 \mathrm{~mL}$ of n-hexane to the gel in the mould. The solvent exchange was allowed to proceed at room temperature for $24 \mathrm{~h}$. Thereafter, the n-hexane was replaced. This procedure was performed three times in total.

\section{Ambient pressure drying}

After the solvent exchange, the n-hexane was drained away leaving just enough to barely cover the surface of the gel. The mould was then covered and the n-hexane left to evaporate naturally at room temperature for a minimum period of $96 \mathrm{~h}$. The best results towards achieving monolithicity of the silica aerogel were attained by uncovering the mould for 10-20 s after every $24 \mathrm{~h}$. This exposure allowed the n-hexane that evaporated from the gel pores to escape, thereby leaving only silica aerogel. This exposure was repeated daily for 6 days. The silica aerogel formed was crystalline in appearance (Figure 2).
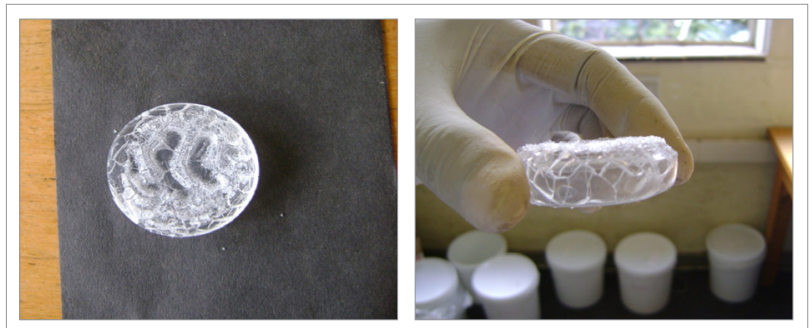

Figure 2: $\quad$ Silica aerogel after 6 days of drying at ambient pressure and temperature.

The silica aerogel was broken into parts of $9 \mathrm{~g}$ each. Each part was then ground to powder using a mill for $25 \mathrm{~min}$. To characterise the silica aerogel powder, samples were taken and subjected to X-ray diffraction (XRD) analysis. The results of XRD on the silica aerogel powder are shown in Figure 3.

The results indicate that the silica aerogel powder obtained by this method is amorphous and not crystalline. In other words, it has no uniform 


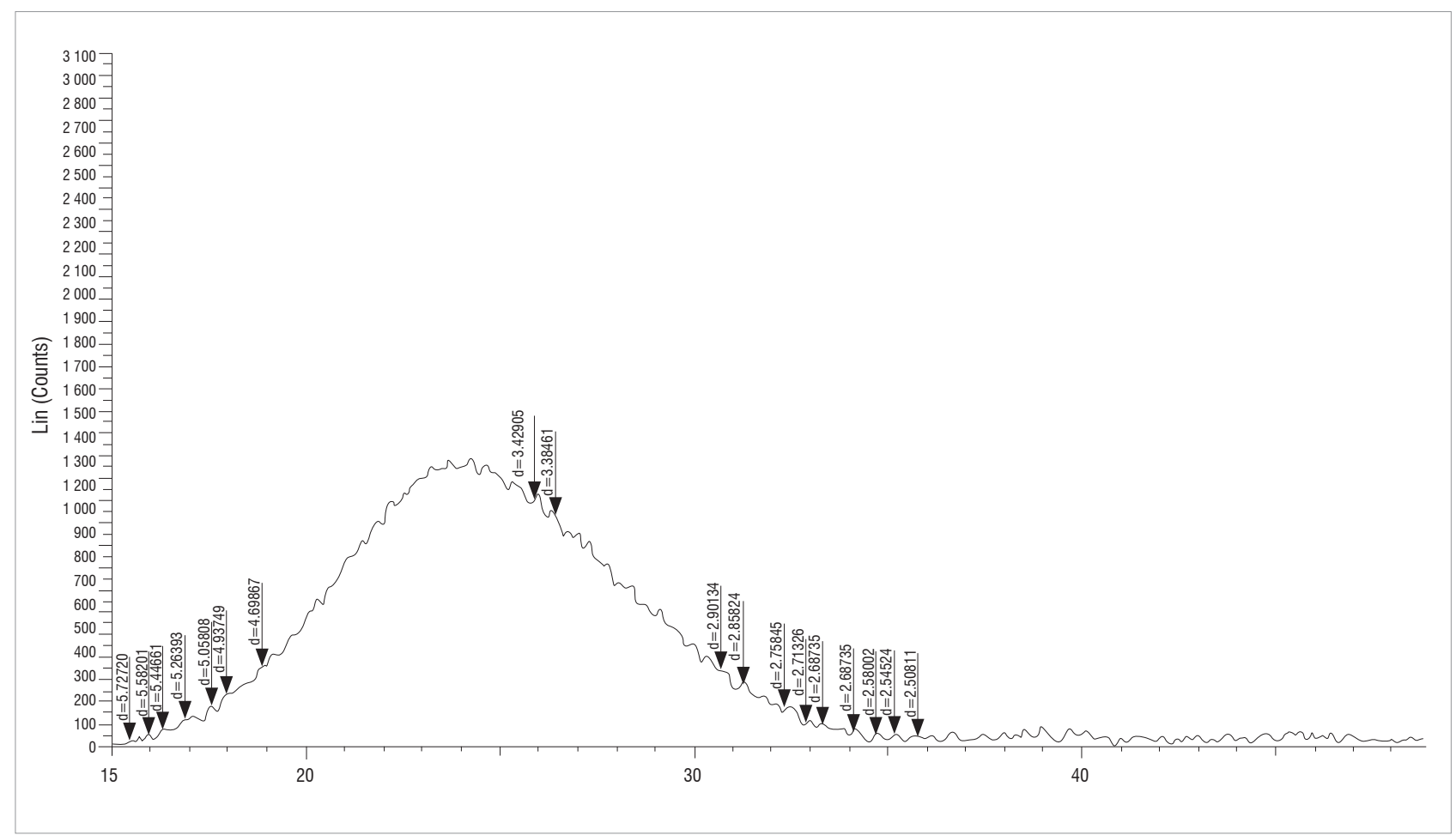

Figure 3: X-ray diffraction image of silica aerogel powder.

structural arrangement. To determine the elemental composition of the silica aerogel powder, an analysis was carried out using energy dispersive X-ray analysis using a scanning electron microscope (SEM) with 'Oxford XMAS' software. The spectrum obtained is illustrated in Figure 4.

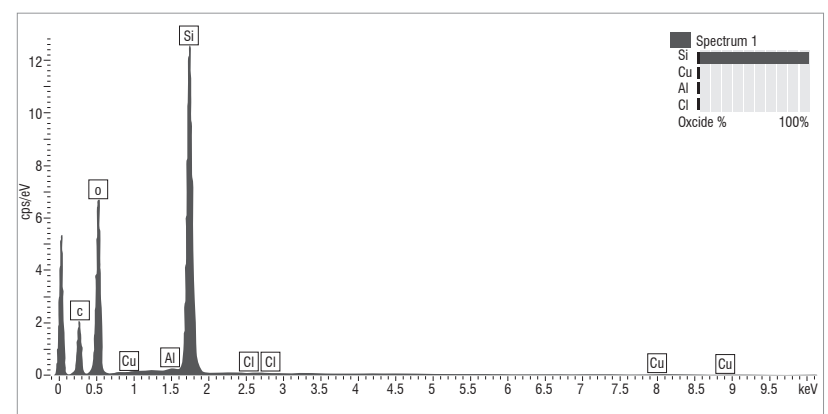

Figure 4: Atomic composition of silica aerogel powder.

The silica aerogel powder consisted predominantly of silicon and oxygen atoms. SEM and transmission electron microscopy (TEM) were used to evaluate the physical nature of the produced silica aerogel powder; these results are illustrated in Figures 5 and 6.

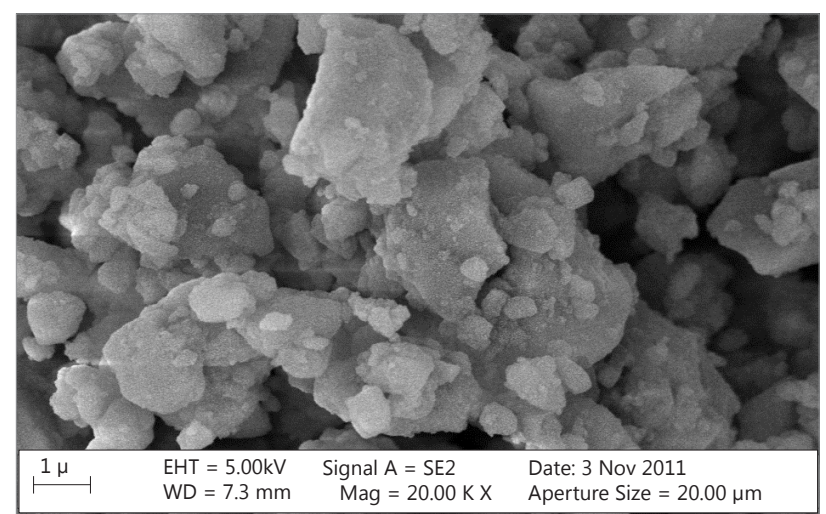

Figure 5: Scanning electron micrograph of silica aerogel powder.

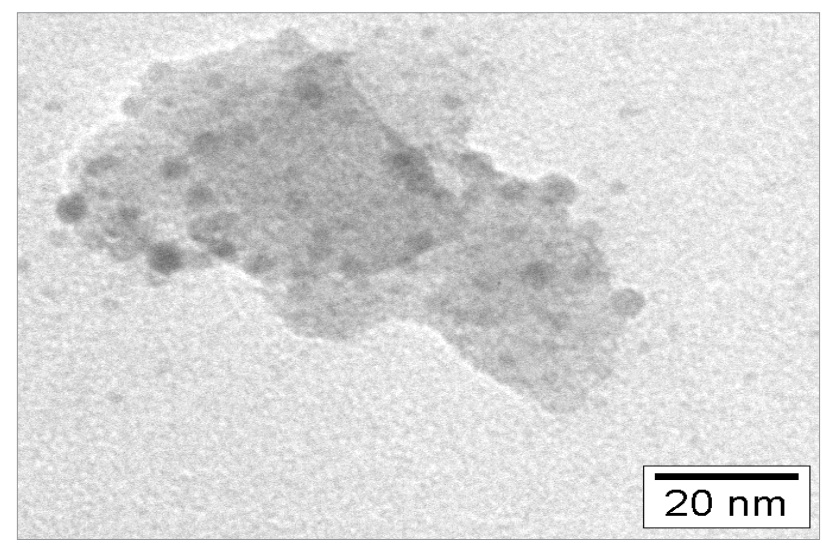

Figure 6: Transmission electron micrograph of silica aerogel powder.

Analysis of the SEM images (Figure 5) illustrates that silica aerogel clusters were formed. Topographical features of the clusters consisted of individual secondary particles loosely aggregated together. Analysis of the TEM images (Figure 6) confirms the presence of nanoparticles, of average width less than $50 \mathrm{~nm}$. In essence, analysis of Figures 5 and 6 conclusively validates that nanosized silica aerogel powder was produced. The resultant nanosized silica aerogel powder was added as a nanodielectric to the vegetable oils (linseed oil and castor oil) to form liquid nanocomposite dielectrics.

\section{Liquid nanocomposite dielectrics}

Vegetable oils are manufactured from agricultural products and are therefore a natural source. Vegetable oils are considered environmentally acceptable because of their biodegradable nature. ${ }^{2,5}$ In this study, we investigated four categories of samples: (1) virgin linseed oil, (2) $5 \%$ weight addition of silica aerogel powder to virgin linseed oil (nanomodified linseed oil), (3) virgin castor oil and (4) 5\% weight addition of silica aerogel powder to virgin castor oil (nanomodified castor oil). The experimental procedures were performed under rigorous and methodological conditions to prevent the inclusion of impurities and moisture in the vegetable oil samples. 
One of the most important insulating properties of dielectric materials is resistivity (conductivity). ${ }^{21}$ There is considerable evidence illustrating that the lower the conductivity of a liquid dielectric, the lower is the dielectric constant. ${ }^{21}$ Therefore, in this study, the performances of the liquid dielectrics were based on measurement of conduction currents. The circuit shown in Figure 7 was used for the measurement of the conduction currents.

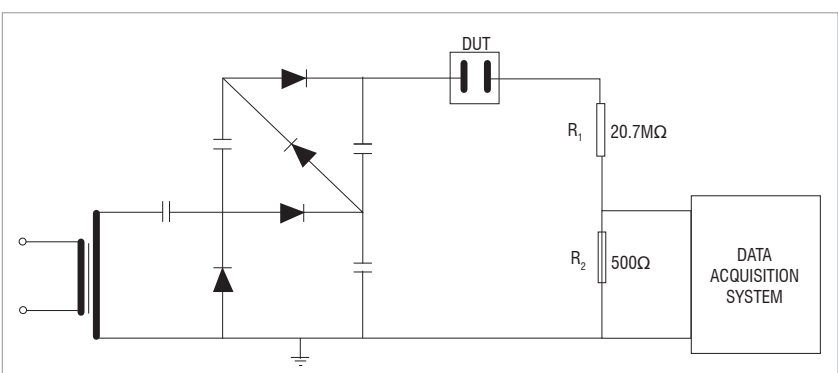

DUT, device under test

Figure 7: Schematic of a DC conduction current test circuit.

A high DC voltage was generated using a two-stage Walton-Cockroft voltage double circuit. The details of the operating principle of the Walton-Cockroft circuit can be found in Everhart ${ }^{28}$. The high DC voltage is applied to the device under test, which consists of a parallel plane electrode arrangement plus the vegetable oil samples. This electrode arrangement is illustrated in Figure 8 (not drawn to scale for easier illustration). In this investigation, only a positive voltage was applied to the device under test. Resistors $R_{1}$ and $R_{2}$ were used for current limiting as well as conduction current measurements. $R_{1}$ and $R_{2}$ were designed to have minimal effect on the pre-breakdown phenomena of the vegetable oil samples. Although it is acknowledged that the external circuit may have had an influence on the pre-breakdown events in the vegetable oil samples, because this study included the virgin vegetable oils on their own as controls, any external circuit influence would have been common to both sets of experiments. Further analysis of the influence of the external circuit was therefore not considered.

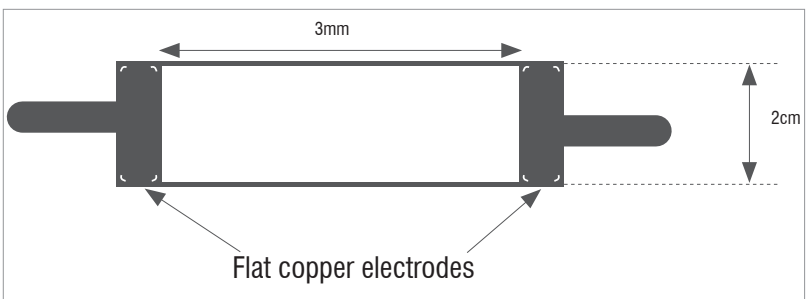

Figure 8: Schematic of a parallel plane electrode test cell.

The measurement system (i.e. the data acquisition system indicated in Figure 7) consisted of a probe connected across the 500-0hm resistor $\left(R_{2}\right)$ feeding a voltage signal in the order of millivolts into a picoscope. The picoscope was in turn connected to a computer for display and storage of the data. In order to capture as much detail as possible in regard to the variation of the voltage across $R_{2}$, the picoscope was calibrated using the following configuration: a time per division of $10 \mathrm{~s} /$ div; a sample interval of $382 \mu \mathrm{s}$; a sample rate of $2.618 \mathrm{kS} / \mathrm{s}$; a total number of samples of $200 \mathrm{MS}$ and a resolution enhancement of 16 bit. The data stored in the computer over a 1-min period was voltage, in the order of millivolts, across $R_{2}$. Because resistor $R_{2}$ was in series with the device under test, the data captured gave an indication of the variation with time of conduction current flowing through the sample. During the analysis, the picoscope software was used to determine the average DC voltage in millivolts across $R_{2}$ within the 1-min test period for a given applied voltage. By using Ohm's Law, this value was then used to calculate the average conduction current flowing through the sample in the 1-min period. The conduction currents calculated were in the order of microamps.

\section{Results}

The breakdown of liquid dielectrics is the ultimate action of the conduction current process. ${ }^{22} \mathrm{It}$ is important to understand the behaviour of the conduction current versus the applied voltage characteristic in the region occurring before breakdown of the liquid dielectric. ${ }^{22}$ The most important challenge encountered with conduction current measurements is attaining stability and reproducibility of the measurements. To overcome this challenge, five liquid dielectric samples were prepared and subjected to the applied DC voltage. The DC voltage was applied to the liquid dielectric sample and the average current over a 1-min period was measured. Thereafter the DC voltage was increased in a stepwise manner and the measurement process was repeated. In general, the conductivity of organic liquid dielectrics is extremely sensitive to impurities. During the interpretation of the relationship between applied voltage and conduction current measurement, more importance should be placed on the general shape of the characteristic than on the magnitude of such currents. ${ }^{22}$

The applied DC voltages versus the DC conduction current measurement results for virgin linseed oil and virgin castor oil are illustrated in Figures 9 and 10, respectively. The characteristic curves for both virgin linseed and castor oil illustrate that the DC conduction current increases approximately linearly with the applied DC voltage. This relationship is synonymous with Ohm's Law. In both oils, the conduction current is ionic in nature and increases linearly with the applied voltage. The presence of ions is postulated but no hypothesis is made as to how such ions are formed. The majority of the ions are thought to be caused by impurities present in the virgin linseed oil and virgin castor oil.

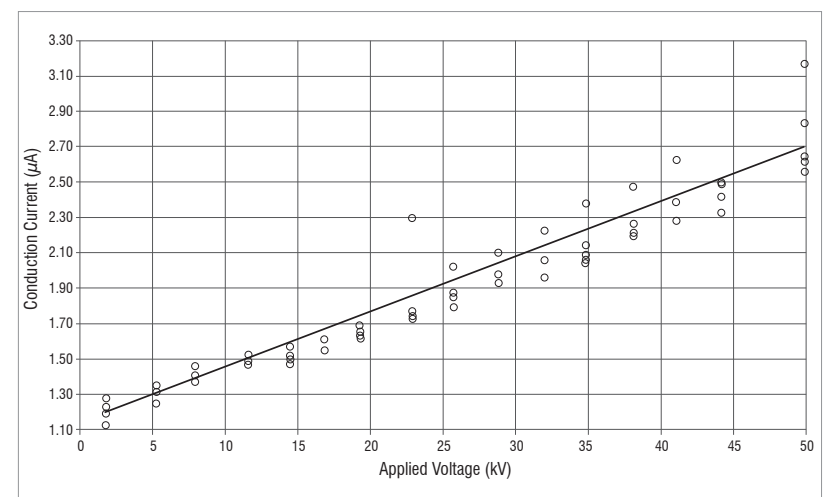

Figure 9: Conduction current measurements for virgin linseed oil using the parallel plane electrode test cell.

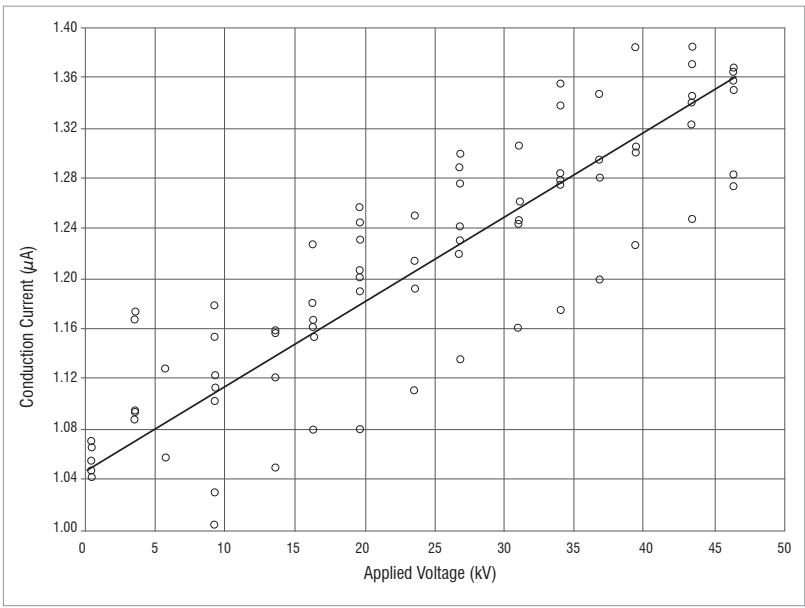

Figure 10: Conduction current measurements for virgin castor oil using the parallel plane electrode test cell.

The applied DC voltage versus the DC conduction current measurement results for nanomodified linseed oil are illustrated in Figure 11. The 
characteristic curve illustrates that two distinct regions exist: (1) a linear region (at lower applied voltage) and (2) a saturation region (at slightly higher voltage). In the linear region, the current increases with the applied voltage until it reaches a relative saturation plateau. The relative saturation plateau signifies the saturation region, where the current increases only slightly with the applied voltage. In the saturation region, the characteristics do not show an absolute saturation value but a small rise in current with increasing applied voltage. Within the saturation region, anomalous conduction currents were measured. We surmise a possible explanation for the anomalous currents. When the direct voltage was applied to the liquid nanocomposite dielectric, the conduction current decreased with time. In some cases, this current decay process was extremely slow. The DC current decayed from a high initial value to a final steady value, which may have been many times less than the initial current. The complete explanation of the anomalous conduction current phenomenon is still lacking. The time taken for the final steady conducting state to be attained and the ratio of the initial to the final conductivity, are dependent on the degree of nanomodification.

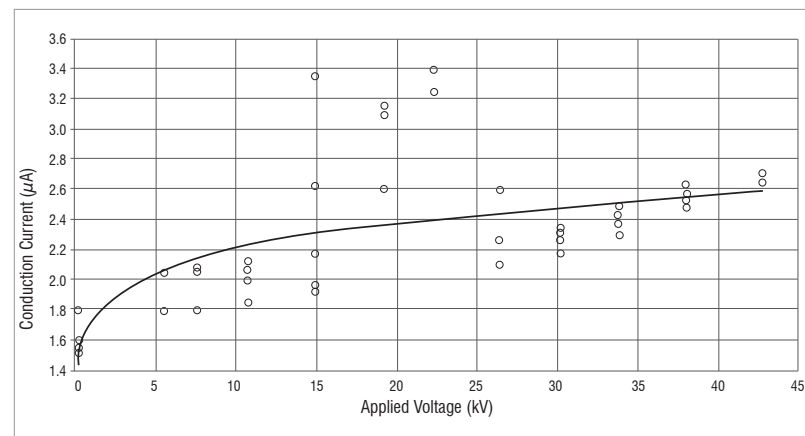

Figure 11: Conduction current measurements for nanomodified linseed oil using the parallel plane electrode test cell.

The applied DC voltage versus the $\mathrm{DC}$ conduction current measurement results for nanomodified castor oil are illustrated in Figure 12. The characteristic curve illustrates that three distinct regions exist: (1) a linear region (at lower applied voltage), (2) a saturation region (at intermediate applied voltage) and (3) an exponential growth region (at higher applied voltage). In the linear region, the current increases with the applied voltage until it reaches a relative saturation plateau. The relative saturation plateau signifies the saturation region, where the current increases only slightly with the applied voltage. In the saturation region, the characteristics do not show an absolute saturation value but a small rise in current with increasing applied voltage. The knee area marks the end of the saturation plateau. Beyond the knee area, the current increases more rapidly. The rapid rise of current with applied voltage in the exponential growth region of the characteristic seems to indicate the imminent breakdown.

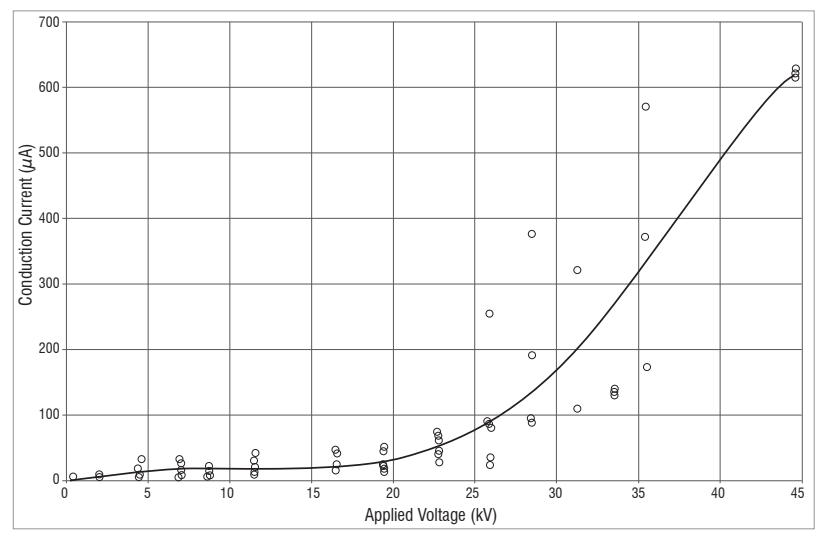

Figure 12: Conduction current measurements for nanomodified castor oil using the parallel plane electrode test cell.

\section{Discussion}

The conduction current characteristics of virgin linseed oil (Figure 9) and virgin castor oil (Figure 10) illustrate a linear growth. However, the DC bias was higher in virgin linseed oil than in virgin castor oil. While virgin linseed oil displayed a linear growth in conduction current (Figure 9), nanomodified linseed oil displayed regions of both linear growth and saturation (Figure 11). Congruently, nanomodified castor oil displayed a region of linear growth, a saturation region and an exponential growth region (Figure 12). In general, the nanomodified vegetable oils had higher conduction currents than the virgin vegetable oils. An interesting observation is that although the conduction current characteristic for virgin linseed oil (Figure 9) had a higher DC bias than that for virgin castor oil (Figure 10), the curve for nanomodified castor oil (Figure 11) had a higher DC bias than that for nanomodified linseed oil (Figure 12). This finding implies that nanomodification increased streamer activity in the vegetable oils. The increased streamer activity was more aggressive in nanomodified castor oil than in nanomodified linseed oil. The exact reason for the increased activity is not yet known and needs to be investigated further. Fabiani et al. ${ }^{4}$ suggest possible explanations for increased pre-breakdown currents in nanostructured materials. Contaminants left by a filler compatibilisation process can worsen the electrical properties of a nanostructured material. ${ }^{4} \mathrm{~A}$ decrease in DC electrical strength and an increase in space charge accumulation have been observed in nanostructured materials. ${ }^{16}$ These changes may occur particularly for those fillers that need a compatibilisation process which can introduce extra ionic species. ${ }^{4}$ Another kind of material contamination is relevant to water absorbed by nanofillers that can be present in the final nanocomposite and dramatically affect its electrical properties. ${ }^{4}$

\section{Conclusion}

We investigated the use of vegetable oils, namely linseed oil and castor oil, in power transformers. Silica aerogel powder was developed in the laboratory and added as a dielectric to the vegetable oils to form liquid nanocomposite dielectrics. The pre-breakdown phenomenon in the liquid nanocomposite dielectrics was then investigated by measuring the DC conduction currents. Higher conduction currents were observed in virgin linseed oil than in virgin castor oil. The nanomodified linseed oil performed better than the nanomodified castor oil. Overall, the addition of nanodielectrics to vegetable oils decreased the dielectric performance of the vegetable oils. Possible reasons for this deterioration in dielectric performance include impurities in the nanodielectrics and moisture inclusion. Although rigorous procedures were followed for the preparation of the liquid nanocomposite dielectric, improved processing methods should be developed.

\section{Authors' contributions}

N.M.I. was the project leader. I.W.S. designed and conducted the experiments. L.C. designed the experiments and wrote the manuscript.

\section{References}

1. Jalal TS, Bodger P. National energy policies and the electricity sector in Malaysia. Third International Conference on Energy and Environment; 2009 Dec 7-8; Melaka, Malaysia. p. 385-392.

2. Koch H. 2020 Vision for the substations. IEEE Power Engineering Society General Meeting; 2007 June 24-28; Tampla, FL, USA. p. 1-10.

3. Brierley RH, Morched AS, Grainger TE. Compact right-of-ways with multivoltage towers. IEEE Trans Power Delivery. 1991;6(4):1682-1689. http:// dx.doi.org/10.1109/61.97707

4. Fabiani D, Montanari GC, Testa L. Effect of aspect ratio and water contamination on the electric properties of nanostructured insulating materials. IEEE Trans Dielectr Electr Insul. 2010;17(1): 221-230. http:// dx.doi.org/10.1109/TDEl.2010.5412021

5. Kirschen DS. Power system security. Power Eng J. 2002;16(5):241-248. http://dx.doi.org/10.1049/pe:20020502

6. Jimoh AA, Mahlasela VS, Nicolae DV. A study of insulation failure in a high voltage current transformer. European Conference on Power Electronics and Applications; 2005 Sep 11-14; Dresden, Germany. p. 1-10. 
7. Deokar SA, Waghmare LM. Impact of power system harmonics on insulation failure of distribution transformer and its remedial measures. 3rd International Conference on Electronics Computer Technology (ICECT 2011); 2011 Apr 8-10; Kanyakumari, India. p. 136-140.

8. Arazoe S, Saruhashi D, Sato Y, Yanabu S, Okabe S, Ueta G. Electrical characteristics of environmentally friendly insulating oils. IEEE Conference on Electrical Insulation and Dielectric Phenomena; 2010 0ct 17-20; West Lafayette, IN, USA. p. 337-340.

9. Martins MAG. Vegetable oils, an alternative to mineral oil for power transformers-experimental study of paper aging in vegetable oil versus mineral oil. IEEE Electr Insul Mag. 2010;26(6):7-13. http://dx.doi. org/10.1109/MEl.2010.5599974

10. McShane CP. Relative properties of the new combustion resistant vegetable oil based dielectric coolants for distribution and power transformers. IEEE Trans Ind Appl. 2001;12:1132-1139. http://dx.doi.org/10.1109/28.936406

11. Oommen TV. Vegetable oils for liquid filled transformers. IEEE Electr Insul Mag. 2002;18(1):6-11. http://dx.doi.org/10.1109/57.981322

12. Li J, Grzybowski S, Sun Y, Chen X. Dielectric properties of rapeseed oil paper insulation. IEEE Conference on Electrical Insulation and Dielectric Phenomena; 2007 0ct 14-17; Vancouver, Canada. p. 500-503.

13. Zhang Z, Li J, Zou P, Grzybowski S. Electrical properties of nano-modified insulating vegetable oil. IEEE Conference on Electrical Insulation and Dielectric Phenomena; 2010 0ct 17-20; West Lafayette, IN, USA. p. 34-37.

14. Hosier IL, Guushaa A, Westenbrink EW, Rogers C, Vaughan AS, Swingler SG. Aging of biodegradable oils and assessment of their suitability for high voltage applications. IEEE Trans Dielectr Electr Insul. 2011;18(3):728-738. http://dx.doi.org/10.1109/TDEl.2011.5931059

15. Choi C, Yoo HS, Oh JM. Preparation and heat transfer properties of nanoparticle-in-transformer oil dispersions as advanced energy efficient coolants. Curr Appl Phys. 2008;8(6):710-712. http://dx.doi.org/10.1016/j. cap.2007.04.060

16. Sharbaugh AH, Devins JC, Rzad SJ. Progress in the field of electric breakdown in dielectric liquids. IEEE Trans Electr Insul. 1978;13(4):249276. http://dx.doi.org/10.1109/TEl.1978.298076
17. Wintenberg AL, Pace MO, Blalock TV, Foust JV. Prebreakdown current pulses in n-hexane. IEEE Trans Electr Insul. 1989;24(1):67-74. http:// dx.doi.org/10.1109/14.19867

18. Lesaint 0 , Tobazeon $R$. Streamer generation and propagation in transformer oil under AC divergent field conditions. IEEE Trans Electr Insul. 1988;23(6):941 954. http://dx.doi.org/10.1109/14.16519

19. Marsden HI, McGrath PB. An optical study of prebreakdown events in ACstressed n-hexane. IEEE Trans Electr Insul. 1991;26(2):266-270. http:// dx.doi.org/10.1109/14.78327

20. Elshazly-Zaghloul M. Conduction current in insulating oils: Components and parameters. IEEE Trans Electr Insul. 1991;26(6):1220-1223. http://dx.doi. org/10.1109/14.108162

21. Jackson W. A résumé of recent work on the anomalous behaviour of dielectric liquids. Journal of the Institution of Electrical Engineers. 1934;75(451):93 110.

22. Zaky $A A$, Tropper $H$, House $H$. Electrical conduction in organic liquids. Br J Appl Phys. 1963;14:651-656. http://dx.doi.org/10.1088/0508$3443 / 14 / 10 / 313$

23. Shi F, Wang L, Liu J. Synthesis and characterization of silica aerogels by a novel fast ambient pressure drying process. Mater Lett. 2006;60:37183722. http://dx.doi.org/10.1016/j.matlet.2006.03.095

24. Ivanov GR, Tomova R, Djambova ST, Nadoliiski M, Dimova-Malinovska D. Functionalized aerogels - new nanomaterials for energy-efficient building Preliminary AFM, Nanoidentation and EIS studies. J Phys Conf Ser 2010;253:1-6. http://dx.doi.org/10.1088/1742-6596/253/1/012077

25. Wei T, Chang T, Lu S, Chang Y. Preparation of monolithic silica aerogel of low thermal conductivity by ambient pressure drying. Journal of American Ceramic Society. 2007;90(7):2003-2007. http://dx.doi.org/10.1111/ j.1551-2916.2007.01671.x

26. Faez T, Yaghmaee MS, Sarkar S. New applications of silica aerogel. Electron J Biol. 2005;1(4):76-80.

27. Soleimani Dorcheh A, Abbasi MH. Silica aerogel: Synthesis, properties and characterization. J Mater Process Technol. 2008;199:10-26. http://dx.doi. org/10.1016/j.jmatprotec.2007.10.060

28. Everhart E. The Cockcroft-Walton voltage multiplying circuit. Rev Sci Instrum. 1953;24(3):221-226. http://dx.doi.org/10.1063/1.1770669 